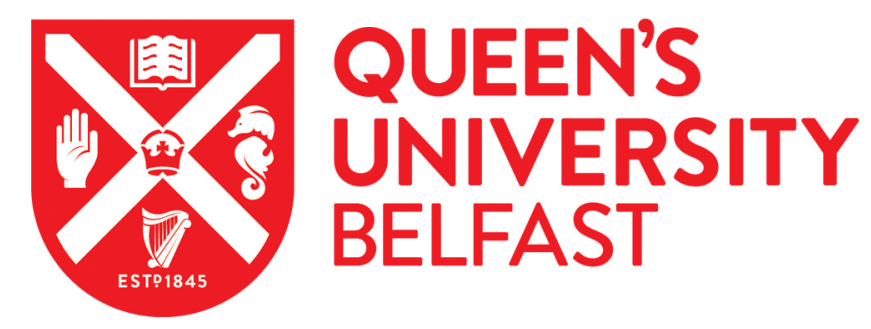

\title{
Effect of BESS Response on Frequency and RoCoF During Under Frequency Transients
}

Brogan, P. V., Best, R. J., Morrow, D. J., McKinley, K., \& Kubik, M. L. (2019). Effect of BESS Response on Frequency and RoCoF During Under Frequency Transients. IEEE Transactions on Power Systems, 34(1), 575583. https://doi.org/10.1109/TPWRS.2018.2862147

Published in:

IEEE Transactions on Power Systems

Document Version:

Peer reviewed version

Queen's University Belfast - Research Portal:

Link to publication record in Queen's University Belfast Research Portal

Publisher rights

(c) 2018 IEEE.

This work is made available online in accordance with the publisher's policies. Please refer to any applicable terms of use of the publisher.

\section{General rights}

Copyright for the publications made accessible via the Queen's University Belfast Research Portal is retained by the author(s) and / or other copyright owners and it is a condition of accessing these publications that users recognise and abide by the legal requirements associated with these rights.

Take down policy

The Research Portal is Queen's institutional repository that provides access to Queen's research output. Every effort has been made to ensure that content in the Research Portal does not infringe any person's rights, or applicable UK laws. If you discover content in the Research Portal that you believe breaches copyright or violates any law, please contact openaccess@qub.ac.uk. 


\title{
Effect of BESS Response on Frequency and RoCoF During Under Frequency Transients
}

\author{
P. V. Brogan, Member, IEEE, R. Best, Member, IEEE, J. Morrow, Member, IEEE, K. McKinley, and M. L. Kubik
}

\begin{abstract}
Battery energy storage system (BESS) services will be of great help when operating power systems at high renewable energy penetrations. This paper demonstrates the requirements for effective frequency and inertia services. Some system operators currently apply scalars to financially reward improved performance. This paper demonstrates a method of validating and improving these scalars by considering the delay time and ramp time of the BESS. The importance of the method used to measure the rate of change of frequency is discussed in the paper. While rate of change of frequency services improve with reduced delivery times, limits are identified where further reductions produce negligible impact. This demonstrates the tangible benefits of a rapid response and that current technology could meet the criteria. A variety of BESS capacities are trialled which demonstrate consistency in performance and the occurrence of diminishing returns.
\end{abstract}

Index Terms-Power system transients, frequency response, renewable energy sources, battery storage plants, renewable energy penetration, ramp rate, delay time

\section{INTRODUCTION}

B ATTERY energy storage systems are undergoing rapid development for power system applications [1]. The primary niche they are filling is in short term power provision, typically delivering power within seconds and providing power for minutes to hours [2]. BESS are well suited to providing power in the period of time between the inertial response of synchronous generators and the frequency dependent response of synchronous generators, HVDC, pumped hydro and peaking plant [3]. Power delivered during this time frame is valuable as it mitigates cascade tripping [4] and damage to the power system due to low frequency or a high rate of change of frequency $(\mathrm{RoCoF})$. Power system services are an increasingly important revenue stream for power providers and lucrative fast frequency response (FFR) services [5] and inertia services are becoming available [6].

This investigation takes a computationally intensive approach to analyze how the operation of a BESS on an islanded power system effects frequency and RoCoF during a loss of generation event. The quantity of BESS along with BESS performance parameters, in terms of delay in operation time and time taken to ramp to full power, were varied. A specific intention of this research is to identify how BESS performance effects frequency and RoCoF services while providing

This work was supported by EPSRC under Grant EP/N508408/1.

P. V. Brogan, R. J. Best, D. J. Morrow are with the School of Electronics, Electrical Engineering, and Computer Science, Queen's University Belfast, BT9 5AH UK (e-mail: paul.brogan@qub.ac.uk)

Ken McKinley is with AES

M. Kubik is with Fluence (e-mail: marek.kubik@ fluenceenergy.com) a method of equating BESS of differing performance, so they can be compensated appropriately [7]. This investigation also demonstrates minimum requirements for participation in frequency and RoCoF services. It is intended that this methodology will be applied to other investigations into BESS siting and sizing in centralized and decentralized schemes.

Power electronic converters, unlike synchronous generators, do not inherently absorb or release power to resist a change in frequency. Reducing system inertia has the greatest effect on frequency stability, whereby an unexpected change in generation or load will have a greater effect on frequency deviation. These frequency events can infringe on customer service agreements, operating constraints, increase wear and tear and can cause cascade tripping and blackouts.

Large power systems often source significant amounts of renewable energy from isolated regions; these regions then begin to experience particularly low inertia issues which can result in events such as the blackout in South Australia in 2016 [8]. The expansion of non-synchronous generation on large systems will eventually cause system wide low inertia issues [9], similar to those addressed on smaller networks.

Synchronous generators units with turbine governors provide two valuable services after an unscheduled generationload imbalance. The first is an inertial response and the second is a droop, or governor response. The inertia (rotational inertia) of a power system resists a change in velocity (angular velocity) due to an applied force (torque); on the power system, this reduces the RoCoF. Reducing RoCoF reduces mechanical stress on connected equipment, allows more time for connected devices to respond to the imbalance and reduces the chances that mains decoupling relays [10] will trigger. The droop response of synchronous generators attempts to maintain nominal frequency by increasing power output as frequency falls. The longer it takes to reach the frequency nadir the more time a synchronous generator has to react and deliver power to improve the frequency nadir. If the frequency falls below certain thresholds then load shedding can take place, which can be costly for consumers and power suppliers.

Ireland has set itself the challenge of sourcing $40 \%$ of its electrical energy from renewable sources by 2020 [11]. To achieve this goal it is anticipated that the Irish power system will need to operate at a system non-synchronous penetration (SNSP) of $75 \%$ for some of the time [12]. At present the Irish power system regularly operates at an SNSP of $60 \%$ and many valuable lessons have been learned in the progress to this point [11]. A shortfall in inertia has been identified as a significant challenge for increasing SNSP [11] and Ireland's transmission system operators (TSOs) have identified BESS has a potential 
solution [12]. The alternative is increased use of the present coping strategies [13], whereby plant output is reduced and additional plant is kept online, resulting in additional expense and emissions.

A study completed by Ireland's TSO concluded that $360 \mathrm{MW}$ of BESS would allow the Irish system to operate securely at an SNSP of 75\% [12]. In this paper BESS with capacities ranging from $50 \mathrm{MW}$ to $500 \mathrm{MW}$ are investigated for validation and planning purposes. A response time of $0.15 \mathrm{~s}$ has been suggested as a cut off by Ireland's TSO in reference to scaling FFR payments with performance [7]. This investigation supports both conclusions but investigates the nuances of the figures.

Queen's University Belfast has worked with AES on their 10 MW BESS array at Kilroot Power Station and with Ireland's TSOs. In the author's opinion a lack of consensus on BESS operation is a barrier to BESS deployment. It is demonstrated in [14] that BESS with FFR can displace significant synchronous generator droop response; but it is demonstrated in Section III-C that FFR will have virtually no effect on RoCoF. It is demonstrated that a BESS must reach full power in less than $300 \mathrm{~ms}$ to deliver significant amounts of energy before maximum RoCoF and thereby displace synchronous inertia services. The nuances of these responses are investigated on the IEEE 39 Bus Model, adapted to represent the Irish System.

A strict interpretation of power system inertia suggests that it only be applied to moving objects that can provide power 'instantly', thus the term synthetic or emulated inertia does have its detractors. In this paper the term RoCoF services is used for a BESS response that can replace aspects of the synchronous inertia response. This investigation is made tractable by studying RoCoF over a moving window of $500 \mathrm{~ms}$; the period over which G59 anti-islanding (mains decoupling) relays typically operate in Ireland and the UK [10]. The use of this RoCoF metric is supported by TSO definitions [6] and also reflects the difficulty in accurately determining RoCoF from waveform measurements over short timescales. Frequency and RoCoF measurements, based on real data, should always be considered as estimates over a specific window, with the accuracy of the estimate being inversely proportional to the measurement length. Conversely, frequency and RoCoF reported by a power simulation can be arbitrarily accurate over arbitrarily short time scales.

This investigation concludes that a BESS that reaches full power in under a second (following the start of an event) is providing an excellent frequency nadir service. If delay times of less than $150 \mathrm{~ms}$ and ramp times of less than $300 \mathrm{~ms}$ are achieved then substantial RoCoF services are realized. These performances should be attainable with existing BESS technology [15].

\section{Power System ANalysis}

In this investigation the performance of the Irish power system, during under frequency transients, is investigated. The standard IEEE 39 Bus System has been adapted in DIgSILENT PowerFactory to reflect the observed behavior of the Irish system. The model was tailored to fit an under-frequency

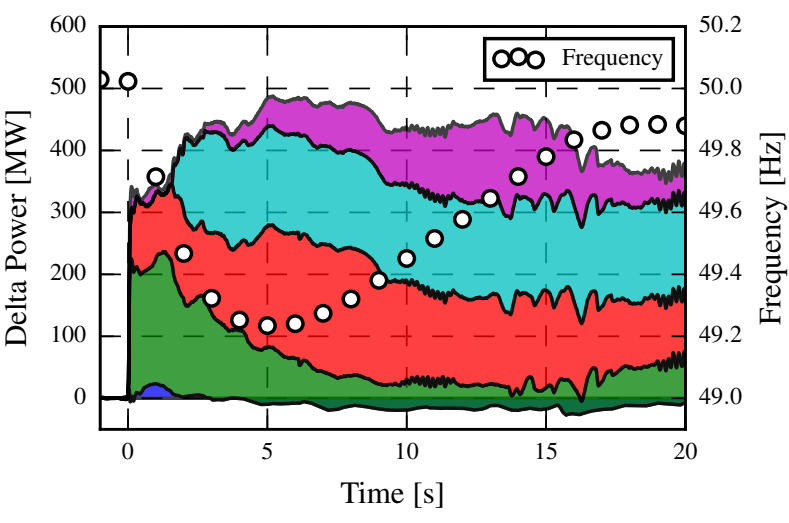

$\square$ Wind $\square$ Gas $\square$ Coal $\square$ HVDC $\square$ Pumped Hydro

Fig. 1. Response of real generators to a significant frequency transient on the Irish power system

transient that was observed by multiple phasor measurement Units (PMUs) at generation sites on the Irish system.

The Irish power system is synchronously isolated as it has no synchronous connections to larger power systems. Ireland has a total dispatchable generation of $10.3 \mathrm{GW}$ [16], has had a peak generation of $6.8 \mathrm{GW}$ and a minimum generation of 2.0 GW. Ireland has a non-dispatchable renewable resource of $4.1 \mathrm{GW}$ with $3.7 \mathrm{GW}$ of that coming from wind; this is expected to increase to $7.1 \mathrm{GW}$ by 2026 . In 2016 Ireland sourced approximately $24 \%$ of its energy from renewable sources, regularly operating at a wind penetration exceeding $50 \%$. These factors couple to make a highly dynamic, relatively large modern power system. In many ways, the Irish system can be considered as a testbed for continental networks that aspire to increase their renewable energy infeed [9].

\section{A. Events on the Irish Power System}

The power system event presented in this section resulted from the loss of the largest committed infeed, a synchronous generator exporting $430 \mathrm{MW}$. This event resulted in a frequency transient with a nadir of $49.23 \mathrm{~Hz}$. A total of fourteen similar events occurred in 2015 [17]. The event studied is typical of the most severe single loss of generation the system can experience. Although the largest single infeeds are the two $500 \mathrm{MW}$ HVDC connections, at present the operation of these assets are frequently curtailed due to transient stability concerns and for static reserve provision.

Shown in Fig. 1 is a plot of generator responses to a frequency transient. The responses from generators of similar fuel are combined for convenience. The data presented in Fig. 1 comes from PMUs that were monitoring $50 \%$ of total generation. The PMU data was scaled with the publicly available half hour metering data from [18].

It is notable from Fig. 1 that wind, although significant at the time $(1.20 \mathrm{GW})$ provided very little inertial response. By contrast, gas and coal provided a substantial response during the first 1.5 seconds, but this rapidly drops off. The static reserve from HVDC also plays a major role in arresting the fall in frequency and restoring it to nominal. Pumped hydro 
was poorly suited for this event as appreciable power begins after 4 seconds and reaches peak power 10 seconds later.

\section{B. Modeling the Irish Power System}

The authors did have access to a DigSILENT model of the Irish power system; however, non-disclosure limitations meant many of the dynamic values, such as generator governor and AVR parameters, were not available for use. For this reason, and to allow the results to be replicated by other institutions, the research was performed on the widely studied IEEE 39 Bus Model. The BESS was placed at Bus 4, as shown in Fig. 2; at present only a single placement at a single bus is being tested, but BESS placement and centralized and decentralized studies are intended.

The effect of BESS operation was tested in DIgSILENT PowerFactory on an IEEE 39 Bus Model that can be used for transient stability assessment [19]; this model has been adapted to represent the Irish system. The load on the standard New England system is $6.10 \mathrm{GW}$, close to Ireland's peak load. Generation during the real system event used to calibrate the model was $4.36 \mathrm{GW}$.

New England is of a similar physical size to many large islanded networks, such as Great Britain, Iceland and New Zealand. Once the inertia provided by Generator 1, Bus 39 (representing the US continental system) is reduced, the 39 Bus System can act as a useful tool for studying large islanded systems. While New England is a little over twice the area of Ireland, it is felt that the similarity in load and generation make it useful for studying potential dynamics of the Irish system.

The model was calibrated with an event that occurred on the Irish system in 2016, during which a generator tripped while exporting $430 \mathrm{MW}, 10.5 \%$ of total load. The inertia of the generators on the 39 Bus Model were modified in order to recreate the observed RoCoF. The governor settings on the model were then adjusted to replicate the observed frequency recovery. The response of static reserve from HVDC and emergency response from pumped hydro were modeled using negative loads .

The loss of generation was simulated by switching in a load of $430 \mathrm{MW}$ and 43 Mvar at Bus 6, which is equivalent to the power drop caused by the loss of the generator. Bus 6 was chosen as there are topological similarities with the real generator trip. As the model has been calibrated to the power system inertia after the trip, there is little difference between switching in an additional load and removing a power source. The differences can diminish further if the loss of a HVDC interconnector is being simulated.

The first step in tuning the grid model involved calibrating the inertia of the power system generators. The inertia of the 39 Bus System is particularly high, so it was reduced from 77.0 GWs to $21.5 \mathrm{GWs}$. The inertia constant of G1 was reduced to $0.275 \mathrm{~s}$ (as its nominal power was retained at $10 \mathrm{GVA}$ ) while the inertia constants of all other generators were set to $2.75 \mathrm{~s}$. After these adjustments the RoCoF on the model matched the observed RoCoF during the first second post event (Fig. 3 and Fig. 4).

During the first second the droop response from generators should be negligible as frequency deviation is small (approx-

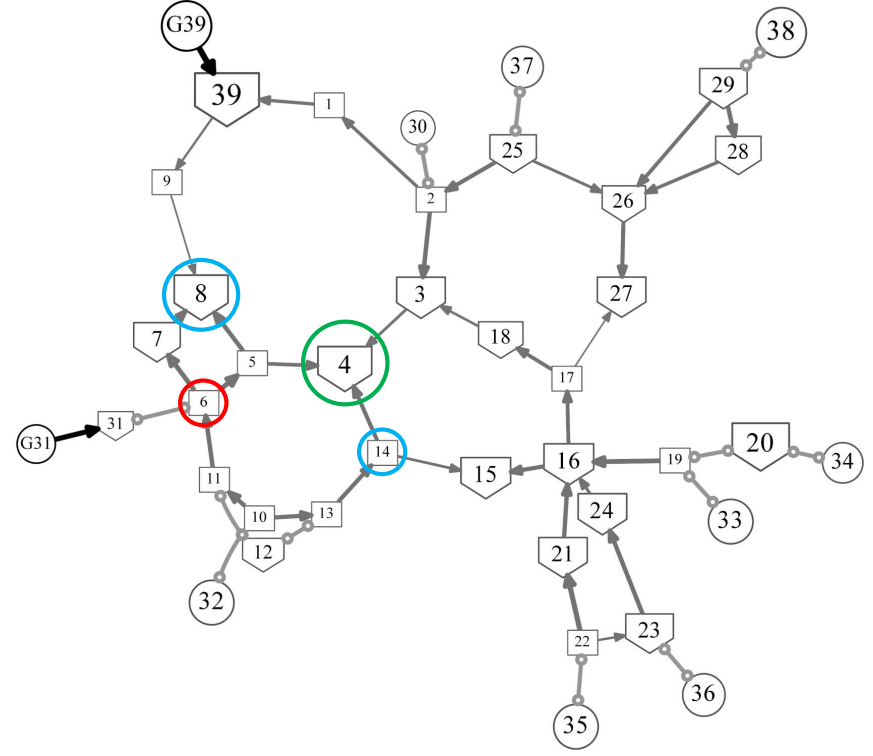

Fig. 2. Scaled graph representation of 39 Bus Model, generation loss occurs at Bus 6, the BESS is placed at Bus 4, HVDC at Bus 14 and pumped hydro at Bus 8 , this reflects the topological positions of the real and potential assets

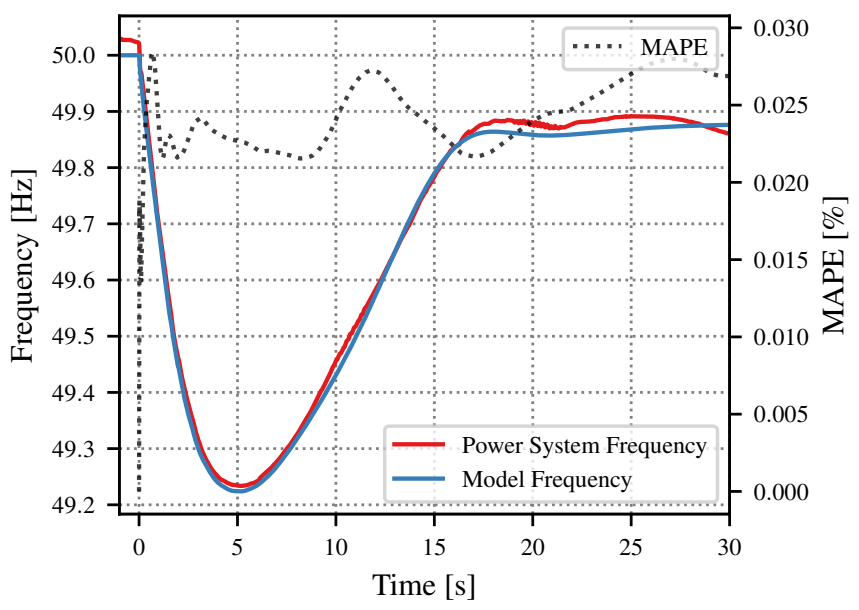

Fig. 3. Frequency on real and modeled power system after loss of generation. The mean absolute percentage error (MAPE) is displayed, it is calculated from $\mathrm{t}=0$ to the specified time.

imately $300 \mathrm{mHz}$ ) and generator time constants tend to be larger than one second. Thus, the power change that slows the frequency drop comes from power system inertia. It is worth noting that the time synchronized PMU data was reported at 50 frames per second, while the power system model was sampled at 100 frames per second. Frequency and RoCoF were returned from every bus on the system for later analysis.

The highest individual RoCoF measurement is observed immediately after the start of the event in both the measured and simulated data. In both cases the trends match, the initial spike in RoCoF measurement from the PMU is believed to arise from the voltage vector shift and rebound. Following this initial RoCoF both measured and simulated data have the same average value and an oscillation of equivalent magnitude and period.

Two significant and deterministic responses that affected the progression of the frequency transient were static reserve 


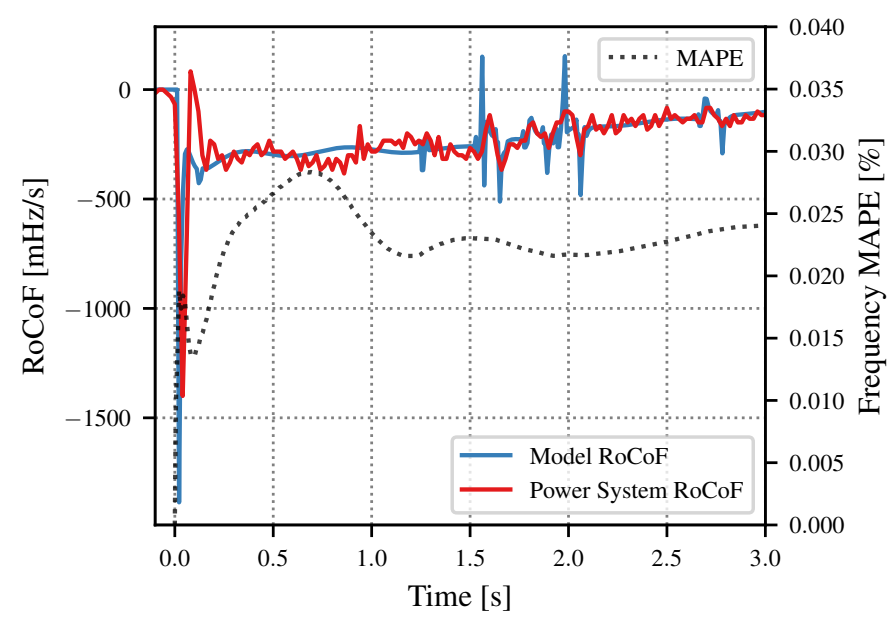

Fig. 4. Average RoCoF on real and modeled system during frequency event. Frequency MAPE is displayed as MAPE becomes undefined when the grid value is zero and applying integration techniques effectively recreates the frequency.

TABLE I

TABLE SHOWING IEEEG1 GOVERNOR SETTINGS IMPLEMENTED ON IEEE 39 Bus Model to Simulate Irish Power System

\begin{tabular}{cccc}
\hline Time Constants & \multicolumn{2}{c}{$\begin{array}{c}\text { Govenor Gain (K) } \\
\text { Torque Fractions (K1-K8) }\end{array}$} \\
\hline & & K & 15 \\
T1 & $0.15 \mathrm{~s}$ & $\mathrm{~K} 1$ & 0.35 \\
$\mathrm{~T} 2$ & $1 \mathrm{~s}$ & $\mathrm{~K} 2$ & 0 \\
$\mathrm{~T} 3$ & $0.6 \mathrm{~s}$ & $\mathrm{~K} 3$ & 0.2 \\
$\mathrm{~T} 4$ & $12 \mathrm{~s}$ & $\mathrm{~K} 4$ & 0 \\
$\mathrm{~T} 5$ & $0.8 \mathrm{~s}$ & $\mathrm{~K} 5$ & 0.3 \\
$\mathrm{~T} 6$ & $0.6 \mathrm{~s}$ & $\mathrm{~K} 6$ & 0 \\
$\mathrm{~T} 7$ & $1 \mathrm{~s}$ & $\mathrm{~K} 7$ & 0.15 \\
15 & $0.15 \mathrm{~s}$ & $\mathrm{~K} 8$ & 0 \\
\hline
\end{tabular}

(from HVDC) and the pumped hydro emergency response. The static reserve response was observed to occur between $1.5 \mathrm{~s}$ and $2 \mathrm{~s}$ after the beginning of the event. The HVDC, as well as the pumped hydro, were simulated with negative loads on Bus 14 and Bus 8, respectively. The static reserve response was simulated with four steps with delay times between 1.5 and $2 \mathrm{~s}$ and ramps of $0.1 \mathrm{~s}$. The effect of the static reserve response, on both the observed and modeled power system, are evident in Fig. 4. The pumped hydro was simulated as having a delay of $1 \mathrm{~s}$ and a ramp of $12 \mathrm{~s}$. The validity of these factors can be extrapolated from Fig. 1 and the effect of their operation on frequency is discussed in Section III-B.

The governors controlling the synchronous generators G2 through G9, on the 39 Bus Model employed in DIgSILENT, are IEEEG1 models [20]. No governor is applied to G1, and G10 was left unaltered. Shown in Table 1 are the turbine time constants (T1-T8), governor gain (K) and torque fractions (K18). These determine generator output and were adjusted to align observed and simulated data, Fig. 3 and Fig. 4.

\section{Modeling a BESS Response}

A negative load was employed in DIgSILENT to replicate the power output of BESS operating with varying operational parameters. The first parameter chosen was BESS power, ranging from $0 \mathrm{MW}$ to $500 \mathrm{MW}$ in steps of $50 \mathrm{MW}$. For

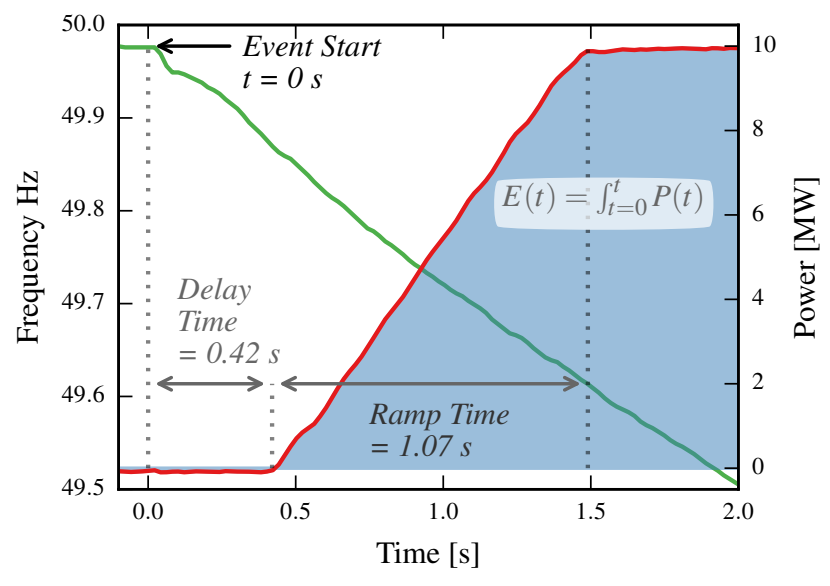

Fig. 5. Plot of real BESS response, displaying start time, delay time and ramp time

each BESS power various BESS operation parameters were simulated, these parameters being delay time and ramp time.

The plot in Fig. 5 is obtained from a PMU monitoring the 10 MW BESS at Kilroot Power Station, and clearly demonstrates the delay time and ramp time. The power response from most conventional plant (Fig. 1) can be approximated with a ramp in power similar to that shown in Fig. 5. In Fig. 1 this response was best observed in HVDC and pumped hydro response, as well as in the initial inertial response of synchronous machines.

Currently the BESS at Kilroot implements an aggressive droop response to ensure eligibility for the FFR service [6]. The BESS output rises linearly as its output is inversely proportional to frequency deviation which is falling linearly during this period (Fig. 5). It should also be noted that the delay time observed in Fig. 5 results predominantly from the time taken for the frequency to drop below the BESS controller's frequency deadband.

The static reserve response of HVDC is observed to have a longer delay time $(>1.5 \mathrm{~s})$ but a much shorter ramp time $(\approx 100 \mathrm{~ms})$. A step change in power is initiated due to an under-frequency condition, this may largely determine the delay time. The ramp time is only limited by technology or grid considerations. Similar observations can be made for pumped hydro. The inertial response from synchronous generators can be modeled with a delay time in the region of a millisecond and a ramp time of around $10 \mathrm{~ms}$.

In this investigation delay times between $10 \mathrm{~ms}$ and $6 \mathrm{~s}$ were investigated along with ramp rates between $10 \mathrm{~ms}$ and $10 \mathrm{~s}$. For a specified BESS power, 48 different delay times and 52 different ramp times are investigated, resulting in 2,496 different simulations for each BESS power. Nine different installed BESS capacities are examined, plus the null result with 0 MW. Delay and response times were increased in steps of $10 \mathrm{~ms}$ between $10 \mathrm{~ms}$ and $200 \mathrm{~ms}$, then in steps of $20 \mathrm{~ms}$ between $200 \mathrm{~ms}$ and $400 \mathrm{~ms}$, increasing thereafter. The intersection of lines in Fig. 6 and the similar plots in Section III-C indicate where simulations were conducted. 


\section{BESS RESPONSE}

The primary aim of this examination is to determine a method of evaluating the beneficial effects of BESS operation. This method should allow for comparison between BESS with differing operating parameters. This method could be used by system operators when assessing what type of BESS response is best for their system. System operators can then incentivize the desired operating parameters by applying a scalar to service payments, such as implemented in [6]. Equal payments should be made to BESS that provide an equivalent service, as can be determined from the equivalence functions and plots derived.

The effect of the BESS response has intentionally been separated into frequency and RoCoF services, this has been done for a number of reasons. Historically, frequency services have been recognized and compensated, while inertia from synchronous machines was taken for granted and not compensated. Meanwhile, FFR and inertial service payments are in development [7] and have only been made available recently and on very few power systems. The performance requirements for frequency and RoCoF services are also quite different, with frequency services requiring a response in the order of seconds while RoCoF services require responses in the order of a hundred of millisecond. Consequently, a BESS that can provide a RoCoF service should be able to provide a frequency service (provided it has sufficient stored energy), while a BESS operator may not wish to implement an FFR service if no compensation is available as the service is unnecessary.

\section{A. Effect of Delay and Ramp Time on Frequency Nadir}

The frequency nadir (or minimum) is a common method of assessing the severity of a frequency transient. If the frequency falls below certain thresholds then load shedding will occur, which is costly for the system operator and consumers. If the frequency falls too far there is the danger of cascade tripping and localized or system-wide blackouts [8].

Displayed in Fig. 6 is the effect that $350 \mathrm{MW}$ of BESS, operating on the Irish power system model, has on the frequency deviation resulting from the event described in Section II-B. As would be expected a BESS with minimum delay and ramp time has the greatest effect on the power system. The $\mathrm{x}$-axis (delay time) is limited to 5 seconds, as the frequency nadir occurs at this time under normal circumstances. Clearly, power provided after the frequency nadir will have no effect on the nadir.

As an example, $350 \mathrm{MW}$ of BESS with a delay time of $2.2 \mathrm{~s}$ and $0.5 \mathrm{~s}$ ramp time resulted in a frequency nadir of $49.40 \mathrm{~Hz}$, like that experienced in the real event. A similar frequency nadir is experienced with $350 \mathrm{MW}$ of BESS that has a negligible delay time and a ramp time of $5.5 \mathrm{~s}$. It is suggested that BESS with these performances should be compensated equally, as should other technologies that fall along the contour line. Thus, the system benefit of storage technologies which may have very different response characteristics, such as lithium ion, flow batteries, or pumped hydro can be equated.

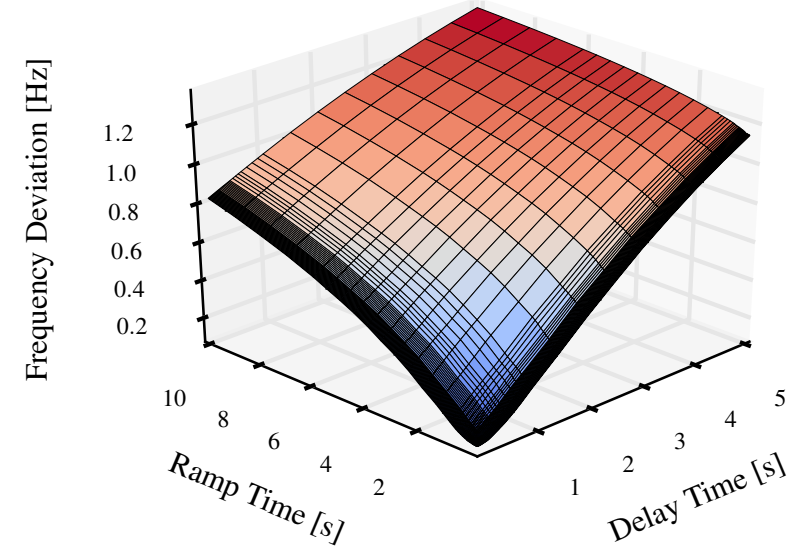

Fig. 6. Effect of $350 \mathrm{MW}$ of BESS on frequency deviation, different delay and ramp times are shown

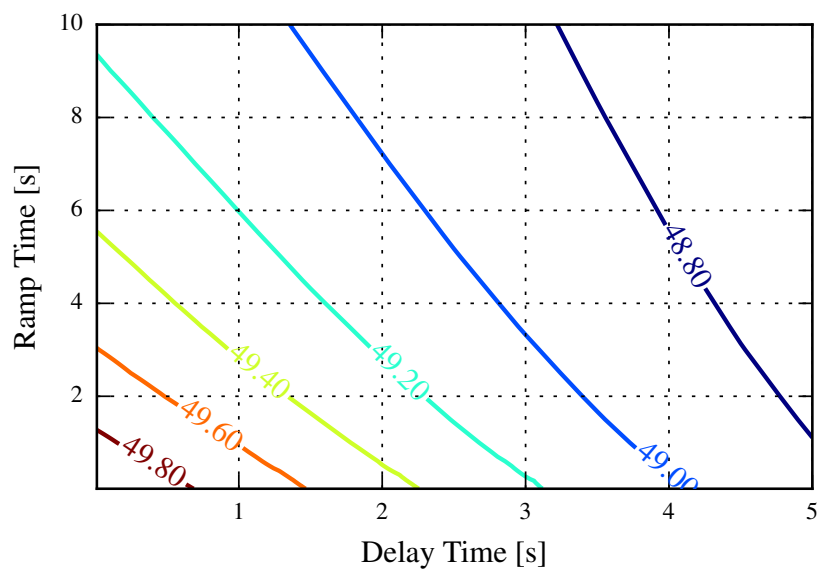

Fig. 7. Effect of $350 \mathrm{MW}$ of BESS on frequency nadir

The contour lines in Fig. 7 are notably linear below a delay time of $2 \mathrm{~s}$ and a ramp time of $4 \mathrm{~s}$. It can be noted that the contour lines in this region have a gradient of approximately -2 . This would suggest a simple linear BESS equivalence, in the form of Equation 1, which could be employed to equate the value of BESS with differing responses. In this case the equivalence value increases with improved performance and could therefore be used directly as a scalar for service payments. The veracity of this simple assessment parameter and its limitations are discussed.

$$
\text { Equivalence }=\left(2 \times T_{\text {Delay }}+T_{\text {Ramp }}\right)
$$

In Equation $1 T_{\text {Delay }}$ is the delay time in BESS operation and $T_{\text {Ramp }}$ is the ramp time (Fig. 5). This type of expression could be expected as it can be supposed that the ameliorating effect on the frequency is directly proportional to the additional power delivered to the power system before the frequency nadir [14]. The amount of energy delivered to the grid will take the form of Equation 2 if the frequency nadir occurs after the ramp is completed (e.g. BESS FFR in Fig. 5, or HVDC static reserve), or Equation 3 if the frequency nadir occurs during the ramp (e.g. pumped hydro), otherwise zero relevant power is delivered. 


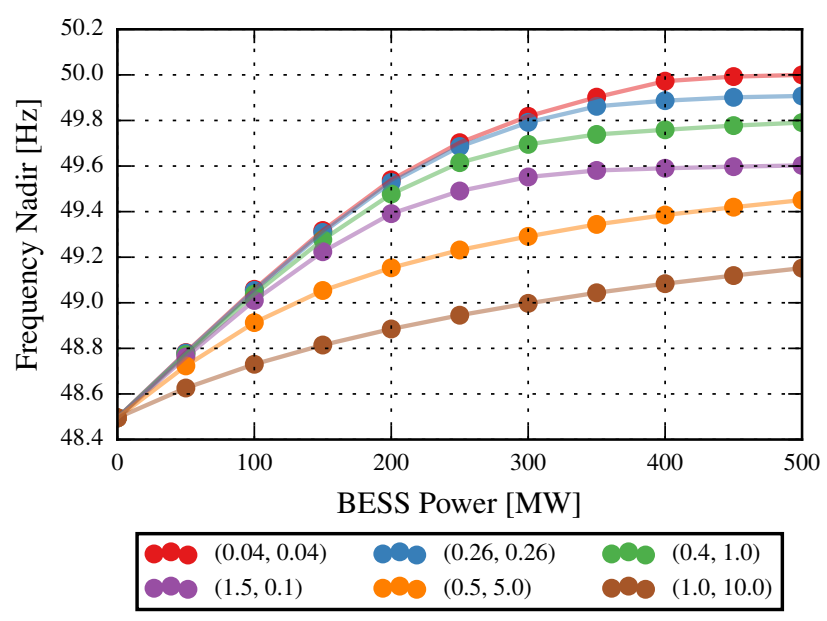

Fig. 8. Effect of BESS power, delay time and ramp time on frequency nadir (delay time [s], ramp time [s])

$$
\begin{gathered}
E_{\text {BESS }}=P_{B E S S} \times\left(T_{\text {nadir }}-\frac{T_{\text {Ramp }}}{2}-T_{\text {Delay }}\right) \\
E_{B E S S}=0.5 \times P_{B E S S} \times\left(\frac{T_{\text {nadir }}-T_{\text {Delay }}}{T_{\text {Ramp }}}\right)
\end{gathered}
$$

Above $E_{B E S S}$ is the additional energy provided by the BESS, as shown in Fig. 5, $P_{B E S S}$ is the maximum power output of the BESS, $T_{\text {Nadir }}$ is the time when the frequency nadir occurs and delay and ramp time are as before. This explains the linearity when $T_{\text {Nadir }}>T_{\text {Delay }}+T_{\text {Ramp }}$ and the breakdown when the condition is infringed. Therefore, reducing delay time has twice the effect of reducing ramp time on frequency nadir while the condition is fulfilled. Reducing ramp time will exponentially increase BESS effectiveness, while the frequency nadir occurs during the ramp.

\section{B. Effect of BESS Power on Frequency Nadir}

Performing tests with multiple sizes of BESS, operating with multiple performances, allows for the direct comparison of BESS of differing performance. Shown in Fig. 8 is a plot of the frequency nadir experienced on the system model when BESS of various parameters are in operation. The parameters chosen reflect the response of some existing power system assets, while other parameters reflect potential operating points for BESS and demand response.

In reverse order a BESS with a response of $(1.0 \mathrm{~s}, 10.0 \mathrm{~s})$ (delay time, ramp time) would reflect the effect that pumped hydro has on frequency nadir. A response of $(0.5 \mathrm{~s}, 5 \mathrm{~s})$ may reflect the droop response from synchronous generators, $(1.5 \mathrm{~s}$, $0.1 \mathrm{~s})$ reflects the response of the HVDC static reserve, $(0.4 \mathrm{~s}$, $1.5 \mathrm{~s})$ reflects the BESS response in Fig. 5. In principle, there is little preventing a BESS implementing a response in the region of $(0.26 \mathrm{~s}, 0.26 \mathrm{~s})$ with appropriate control infrastructure. There is however no benefit for frequency nadir in improving upon a response of $(0.04 \mathrm{~s}, 0.04 \mathrm{~s})$ and this serves as the upper limit of performance.

Power system planners may be interested in the two diminishing returns apparent in Fig. 8; firstly, at increased

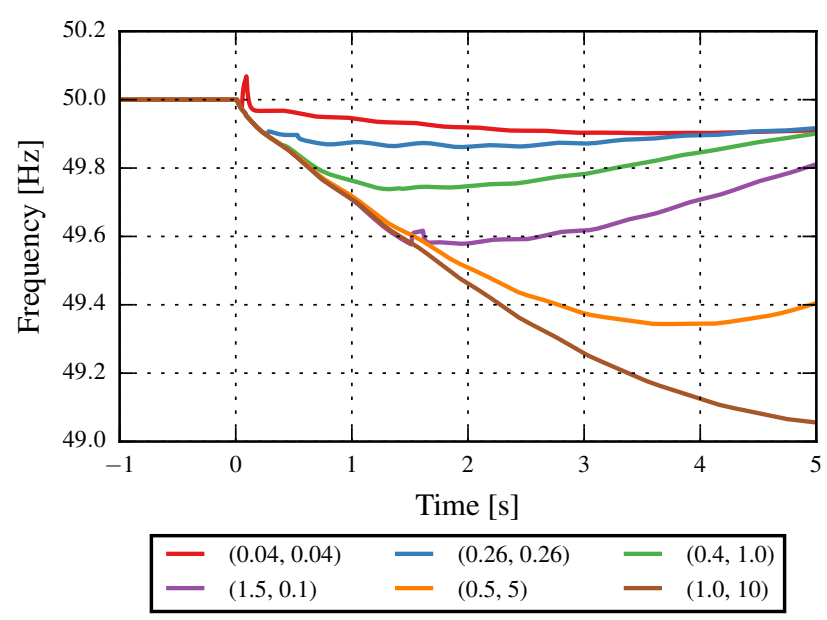

Fig. 9. Plot of frequency transients for $350 \mathrm{MW}$ of BESS operating with varying parameters (delay time $[\mathrm{s}]$, ramp time $[\mathrm{s}]$ )

reaction speed, and secondly, with increased BESS power. The frequency nadir is largely determined by the quantity of additional energy delivered to the system before the nadir is reached. Reducing the combined delay and ramp time from 2 seconds to 1 second may require significant BESS optimization, but if the frequency nadir occurs after 5 seconds, then BESS power delivery before the frequency nadir will not be doubled. It appears that a substantial amount of the positive effect on frequency nadir is achieved with a combined delay and ramp time in the region of 1.5 seconds. Significant improvements beyond this 1.5 second response are only observed at higher BESS powers.

A second effect that causes diminishing returns with increased BESS performance and MW deployment is time to frequency nadir; this is specifically shown in Fig. 9 for $350 \mathrm{MW}$ of BESS with varying performances. BESS operation, both in terms of speed of response and in terms of MW deployment, reduces the time to frequency nadir and reduces the deviation in frequency, as in Fig. 9. While both these outcomes are highly desirable, the reduction in time to frequency nadir reduces the time available for BESS energy delivery, separately the lack of frequency deviation reduces the droop response from synchronous generators. The inflection point in BESS effect on frequency, observed in Fig. 8 between a BESS power of 200 to $250 \mathrm{MW}$, is largely driven by BESS power directly replacing the droop and inertial power response from synchronous generators.

\section{Effect of delay time and ramp time on RoCoF}

The calculation of RoCoF can be noisy, both on a real and simulated system. Much of the noise can be attributed to the fact that RoCoF is the second derivative of phase angle. Differentiation tends to amplify noise, particularly over shorter time periods. RoCoF is therefore sensitive to voltage vector shift and rotor angle oscillations that can imply massive RoCoF values over short time periods.

The RoCoF values were calculated over windows of $100 \mathrm{~ms}$, $250 \mathrm{~ms}$ and $500 \mathrm{~ms}$. The mean value was ineffective as a single deviant value entering or leaving the moving window could 


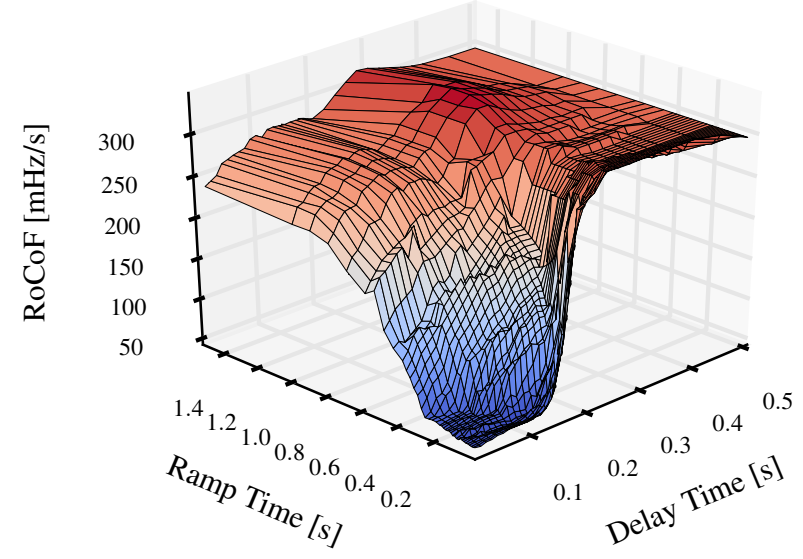

Fig. 10. 3D Plot of Effect of $350 \mathrm{MW}$ of BESS on maximum absolute $\mathrm{RoCoF}[\mathrm{Hz} / \mathrm{s}]$

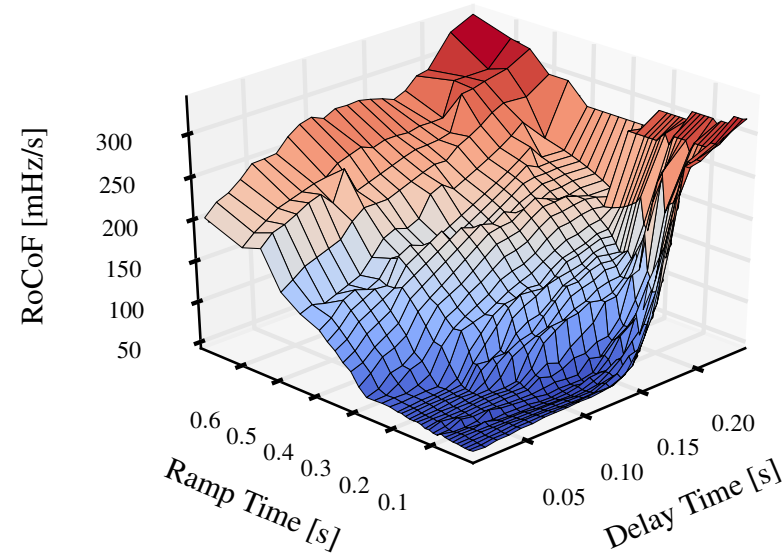

Fig. 11. 3D Plot of Effect of $350 \mathrm{MW}$ of BESS on maximum absolute RoCoF $[\mathrm{Hz} / \mathrm{s}]$, showing region of RoCoF mitigation

significantly disrupt the calculation. In this study the median value over the moving window was employed.

The plots in this section have many similarities with the plots of frequency nadir, however, the plots are noisier and the boundaries more difficult to define in a quantitative manner. Shown in Fig. 10 is the effect of ramp time and delay time on maximum RoCoF for a 350 MW BESS. This figure demonstrates that a delay time of under $250 \mathrm{~ms}$ and a ramp time under $750 \mathrm{~ms}$ is necessary to effect RoCoF.

A fairly linear improvement can be observed in Fig. 11 while the ramp time is between $0.75 \mathrm{~s}$ and $0.30 \mathrm{~s}$ and when delay time is between $0.20 \mathrm{~s}$ and $0.13 \mathrm{~s}$. A relatively simple scalar value could be applied in this region.

There is very little to differentiate BESS performances that lie within the flat, dark blue, area in Fig. 11. This region is approximated as a triangle running between the origin of the plot, to a delay time of $0.15 \mathrm{~s}(\mathrm{ramp}$ time $=0.01 \mathrm{~s})$, to a ramp time of $0.30 \mathrm{~s}$ (delay time $=0.01 \mathrm{~s}$ ) and back to the origin. The shape of this plain remains remarkably consistent as BESS magnitude is varied. This can be observed in Fig. 12, where $100 \mathrm{MW}$ of BESS is in operation.

A contour plot of maximum absolute RoCoF is displayed

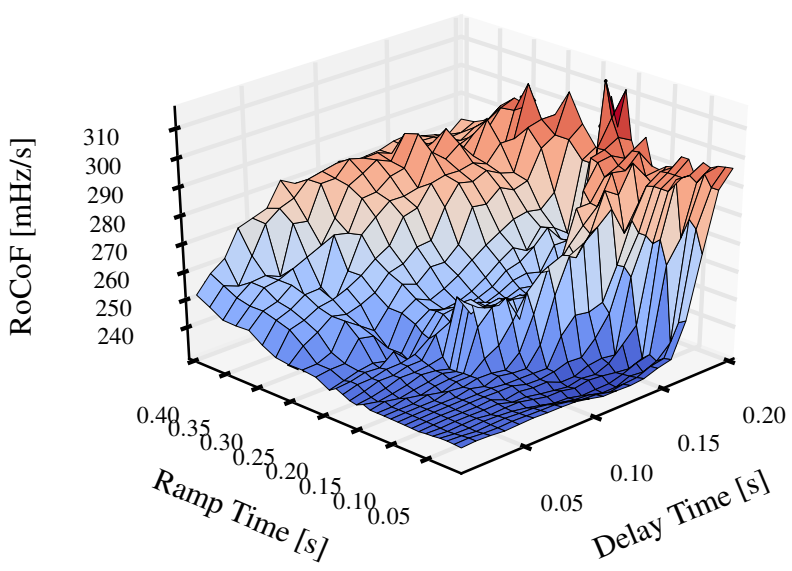

Fig. 12. 3D Plot of Effect of $100 \mathrm{MW}$ of BESS on maximum absolute RoCoF $[\mathrm{Hz} / \mathrm{s}]$, showing area of optimal RoCoF mitigation

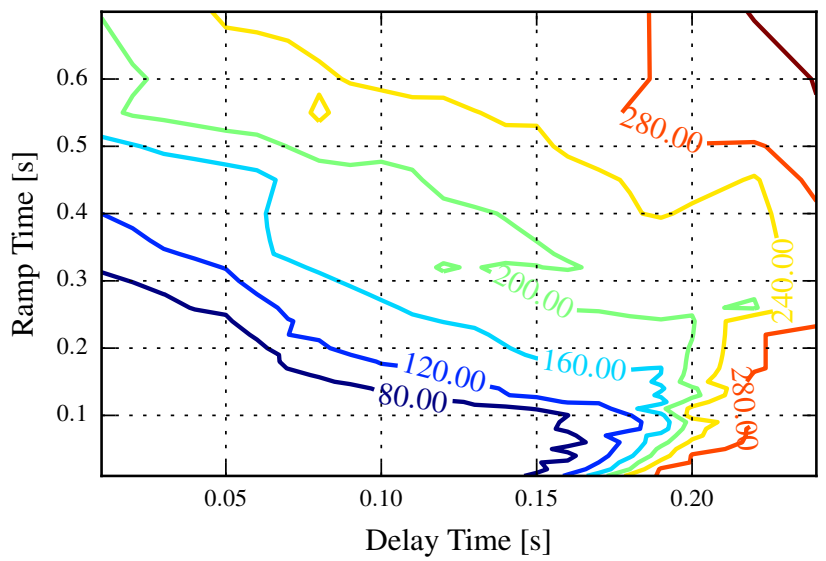

Fig. 13. 3D Plot of Effect of $350 \mathrm{MW}$ of BESS on maximum absolute RoCoF $[\mathrm{Hz} / \mathrm{s}]$, showing area of optimal RoCoF mitigation

in Fig. 13, this can be interpreted in the same way as Fig. 7. BESS that lie on contour lines should have the same efficacy at alleviating RoCoF. It can be noted that the contour lines in Fig. 13 are significantly more complex than the lines in Fig. 7, this can be attributed to the increase in complexity moving from frequency to RoCoF.

If the time over which RoCoF is measured or the method is changed, then the BESS performance requirements change. For this method to be applied to other systems and other scenarios, the detection method must be stipulated. It was observed that as the window for RoCoF calculation was reduced, below $500 \mathrm{~ms}$, the results suffer from increased noise. Over shorter time periods the plain in Fig. 12 reduces in size towards the origin.

\section{Effect of BESS power on RoCoF}

The effect of delay and ramp time on maximum RoCoF has primarily been demonstrated for $350 \mathrm{MW}$ of BESS. To test the consistency of the results, various BESS capacities with the same delay and ramp times are compared. This test also identifies how the staged implementation of BESS 


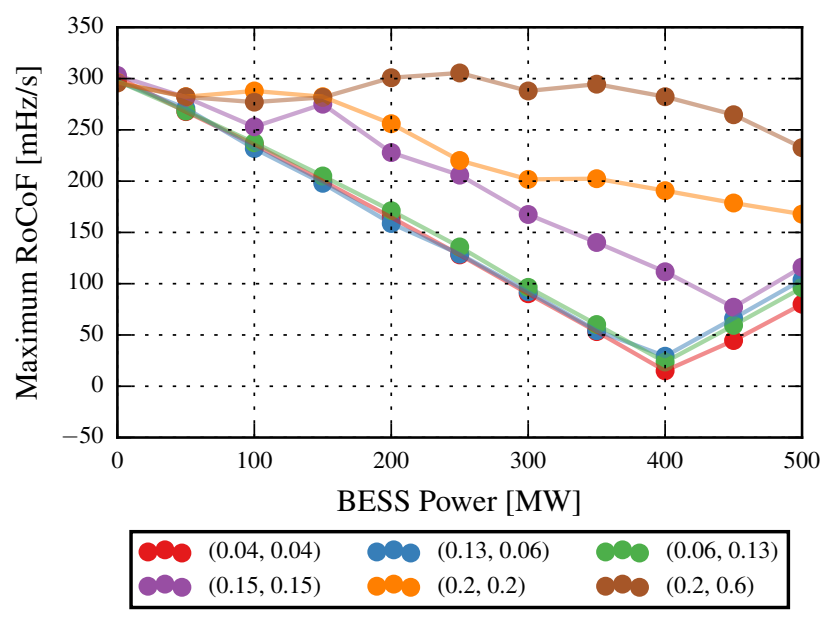

Fig. 14. Effect of BESS power, delay time and ramp time on frequency nadir (delay time [s], ramp time [s])

should affect the power system and when increasing BESS deployment may stop being beneficial. Six performances are chosen for investigation. Three performances are considered optimal, two are considered satisfactory and one is on the limit of what could be considered a RoCoF service.

The $(0.04 \mathrm{~s}, 0.04 \mathrm{~s})$ performance is very fast, but potentially realizable if detection, control and ramp rates are pushed to their limit. If engineers wish to limit RoCoF measured over time periods in the region of $100 \mathrm{~ms}$ or below, then this type of performance will be required. Performances of $(0.13 \mathrm{~s}, 0.06 \mathrm{~s})$ and $(0.06 \mathrm{~s}, 0.13 \mathrm{~s})$ represent slightly less stringent parameters that nevertheless lie on the planar region of plots Fig. 11 and Fig. 12 where optimal performance is indicated.

Two acceptable performances are investigated with responses of $(0.15 \mathrm{~s}, 0.15 \mathrm{~s})$ and $(0.20 \mathrm{~s}, 0.20 \mathrm{~s})$. These figures were chosen as they represent BESS responses that could realistically be achieved in the near term. The performances also represent points on the scaling path from optimal performance to negligible performance. The final performance investigated was $(0.20 \mathrm{~s}, 0.6 \mathrm{~s})$ and represents the performance limit of RoCoF reduction Fig. 13.

Displayed in Fig. 14 is the effect varying BESS power has on maximum RoCoF. It can be observed that there is virtually nothing to differentiate the three optimal performances. Consequently, a region of operation could be designated that receives equal remuneration.

Increasing operational parameters to $(0.15 \mathrm{~s}, 0.15 \mathrm{~s})$ can be observed to reduce the effectiveness of the BESS by between $50 \%$ and $25 \%$. It can be noted that $200 \mathrm{MW}$ of BESS at $(0.15 \mathrm{~s}, 0.15 \mathrm{~s})$ has the same RoCoF mitigation potential as $100 \mathrm{MW}$ at $(0.13 \mathrm{~s}, 0.06 \mathrm{~s})$. However, at higher powers $400 \mathrm{MW}$ of BESS at $(0.15 \mathrm{~s}, 0.15 \mathrm{~s})$ has the same potential as approximately $280 \mathrm{MW}$ at $(0.13 \mathrm{~s}, 0.06 \mathrm{~s})$.

Differentiating a performance of $(0.15 \mathrm{~s}, 0.15 \mathrm{~s})$ from a performance of $(0.20 \mathrm{~s}, 0.20 \mathrm{~s})$ could be difficult to justify empirically as the effect on RoCoF is clearly affected by BESS power. This demonstrates that optimal BESS performances and negligible performances can be set, but the region between them may be complex.

\section{CONCLUSION}

This investigation has developed a methodology for directly comparing the ameliorating effect of BESS, and other storage technologies, during an observed under frequency transient. The effect on frequency and RoCoF from BESS with varying response parameters (delay time and ramp time) can directly be compared and equated with the contour plots provided. These plots demonstrate requirements for participation in frequency and RoCoF services and a method for scaling payments based response times, as is being introduced on the Irish Power System [7].

For a BESS to have a significant effect on the frequency nadir, following a generation-load imbalance, it is important that the sum of BESS delay time and ramp time is less than the frequency nadir time. It was found that a simple formula (Equation 1) could be used to equate BESS operating with differing delay times and ramp rates; with delay time adversely affecting performance twice as much as ramp rate.

It was found that a combined delay and a ramp time of $0.52 \mathrm{~s}$ provided almost $100 \%$ of the maximum potential reduction of frequency nadir. The method also demonstrates the effect on frequency from the existing HVDC static reserve and $10 \mathrm{MW}$ battery array response. Although the technologies have very different performances (in terms of delay time and ramp time) they have a similar effect on the frequency nadir.

A linear relationship between improvements in the frequency nadir and BESS megawatt deployment was observed up to $250 \mathrm{MW}$. After this point, representing approximately $60 \%$ of the lost generation, the response diminished. The diminishing response is attributed to the BESS shortening the time to frequency nadir and replacing the droop and inertial response from synchronous generators as $\mathrm{RoCoF}$ and frequency deviation are reduced.

The highest value service that BESS can provide, during a generation-load imbalance, is RoCoF reduction. This is the case as a rapid power response is the first service a BESS can provide after a fault and it complements the services that follow it. In this study a BESS could only qualify for a RoCoF service (over $500 \mathrm{~ms}$ ) if it had a delay time of less than $0.20 \mathrm{~s}$ and a response time of less than $0.75 \mathrm{~s}$. As the delay time and ramp time approached $0.15 \mathrm{~s}$ and $0.30 \mathrm{~s}$ (respectively) the performance was observed to reach an optimal value. Within this relatively large triangular region the RoCoF service was consistent. Performance dropped with increased delay and ramp time, in a similarly manner to the frequency nadir service, but the relationship was complex.

This investigation has remained technology agnostic and is meant in large part to allow direct comparisons between differing technologies (e.g. BESS, droop and HVDC static response). However, the timescales detailed for frequency and RoCoF services can be used to select for particular technologies where response times and ramp rates are known. Effectively no technologies are excluded due to energy capacity limitations (e.g. supercapacitors) as the time frames under consideration are short. At present most inverter based battery storage technologies should be able to meet the requirements [21], as-well-as super capacitor, flywheel and super conducting 
magnet technologies. The Li-ion batteries at AES Kilroot have demonstrated the potential to respond in under $40 \mathrm{~ms}$ to an event and should have the ability to ramp to full power in $100 \mathrm{~ms}$.

The computationally intensive approach used in this paper has only been applied to a single system state, however it is intended to apply this methodology to other problems and system states. In future work, the power system response at both observed low power system inertias and projected low inertias will be investigated. BESS placement, in both centralized and decentralized applications, will be investigated; as well as the relationship between fault location and BESS location.

\section{ACKNOWLEDGMENT}

The authors would like to thank AES UK \& Ireland, Eirgrid/SONI, The Utility Regulator, and Northern Ireland Electricity for their valuable support.

\section{REFERENCES}

[1] X. Luo, J. Wang, M. Dooner, and J. Clarke, "Overview of current development in electrical energy storage technologies and the application potential in power system operation," Applied Energy, vol. 137, pp. 511536,2015

[2] F. Teng, V. Trovato, and G. Strbac, "Stochastic scheduling with inertiadependent fast frequency response requirements," IEEE Transactions on Power Systems, vol. 31, no. 2, pp. 1557-1566, 2016.

[3] National grid, "frequency response services". [Online]. Available: https://www.nationalgrid.com/uk/electricity/balancing-services/ frequency-response-services

[4] M. H. Athari and Z. Wang, "Impacts of wind power uncertainty on grid vulnerability to cascading overload failures," IEEE Transactions on Sustainable Energy, vol. 9, no. 1, pp. 128-137, 2018.

[5] D. Greenwood, K. Y. Lim, C. Patsios, P. Lyons, Y. S. Lim, and P. Taylor, "Frequency response services designed for energy storage," Applied Energy, vol. 203, pp. 115-127, 2017.

[6] Single electricity market committee (ireland), "ds3 system services tariffs and scalars sem committee decision sem-17-080". [Online] Available: https://goo.gl/C1JV67

[7] EirGrid/SONI, "Consultation on ds3 system services enduring scalar design," 4th July 2017.

[8] A. Bloom, U. Helman, H. Holttinen, K. Summers, J. Bakke, G. Brinkman, and A. Lopez, "It's indisputable: Five facts about planning and operating modern power systems," IEEE Power and Energy Magazine, vol. 15, no. 6, pp. 22-30, 2017

[9] A. Ulbig, T. S. Borsche, and G. Andersson, "Impact of low rotational inertia on power system stability and operation," IFAC Proceedings Volumes, vol. 47, no. 3, pp. 7290-7297, 2014.

[10] A. Dyśko, I. Abdulhadi, X. Li, and C. Booth, "Assessment of risks resulting from the adjustment of rocof based loss of mains protection settings phase ii," University of Strathclyde, ref: $N G C / L O M / T R / 2013$ $001 b, 2013$.

[11] D. Flynn, M. Power, and M. O’Malley, "Renewables integration, flexibility measures and operational tools for the ireland and n. ireland power system," Société de l'électricité, de l'électronique et des technologies de l'information et de la communication, 2016.

[12] Eirgrid/soni, "rocof alternative \& complementary solutions project phase 2 study report". [Online]. Available: http://www.eirgridgroup.com/site-files/library/EirGrid/ RoCoF-Alternative-Solutions-Project-Phase-2-Report-Final.pdf

[13] National grid, "system needs and product strategy". [Online]. Available: https://goo.gl/AGRFKT

[14] P. Brogan, A. Alikhanzadeh, R. J. Best, D. J. Morrow, and M. L. Kubik, "Fast frequency response requirements for replacement of observed generator response during under frequency transients.” cigré, May 2017.

[15] T. Feehally, A. J. Forsyth, R. Todd, M. P. Foster, D. Gladwin, D. A. Stone, and D. Strickland, "Battery energy storage systems for the electricity grid: Uk research facilities," in 8th IET International Conference on Power Electronics, Machines and Drives (PEMD 2016), April 2016, pp. 1-6.
[16] Eirgrid/soni, "all-island generation capacity statement 20172026". [Online]. Available: http:/www.eirgridgroup.com/site-files/ library/EirGrid/4289_EirGrid_GenCapStatement_v9_web.pdf

[17] Eirgrid/soni, "all-island transmission system performance report 2015". [Online]. Available: http://www.eirgridgroup.com/site-files/ library/EirGrid/AITSPR2015_FINAL_TO_RAS.pdf

[18] Semo, "single electricity market operator". [Online]. Available: http://www.sem-o.com/

[19] T. Athay, R. Podmore, and S. Virmani, "A practical method for the direct analysis of transient stability," IEEE Transactions on Power Apparatus and Systems, no. 2, pp. 573-584, 1979.

[20] I. C. Report, "Dynamic models for steam and hydro turbines in power system studies," IEEE Transactions on Power Apparatus and Systems, vol. PAS-92, no. 6, pp. 1904-1915, Nov 1973.

[21] X. Luo, J. Wang, M. Dooner, and J. Clarke, "Overview of current development in electrical energy storage technologies and the application potential in power system operation," Applied Energy, vol. 137, pp. 511536,2015

Paul Brogan received M.Sc and Ph.D. degrees from Queen's University Belfast in 2009 and 2016, respectively. Dr Brogan's Ph.D. research was in wide-area monitoring, protection and control, utilizing PMU measurements and for application to distribution assets. He is pursuing post-doctoral research in the Large Scale Storage for Network Services with a focus on monitoring battery operation and optimization.

Robert J Best (M'09) received the MEng and Ph.D. degrees from Queen's University Belfast, UK, in 2004 and 2008, respectively. Dr Best is currently a Lecturer with the Energy Power and Intelligent Control (EPIC) cluster at Queen's University Belfast, with research interests in power system operation and control, distributed generation, and electric machinery. Dr Best is a Member of the IEEE.

D John Morrow (M'99) was born in Dungannon, Northern Ireland, in 1959. He received the B.Sc. and Ph.D. degrees from Queen's University Belfast (QUB), Belfast, U.K., in 1982 and 1987, respectively. He is now a Professor in electrical engineering at QUB, where he has been since 1987, with research and consulting interests in electric power systems, power system instrumentation, and embedded generation control and protection. Prof. Morrow is a member of the IET and also a member of the IEEE Excitation Systems Subcommittee.

Kenneth McKinley came up through industry by means of an electrical apprenticeship before received a Higher National Diploma in Electrical \& Electronic Engineering from the University of Ulster in 1984, he was head of the Electrical C\&I department in Kilroot Power Station from 2013 to 2016. Since 2016 he has worked as an energy storage engineer for AES in Europe.

Marek L Kubik received his MEng from Durham University in 2009, and an $\mathrm{PhD}$ from the University of Reading in 2013, which focused on the challenges of integrating variable renewable energy within existing markets. Marek currently works for Fluence, the leading global energy storage technology and services provider. He played an instrumental role in the development of the 10 MW Advancion Energy Storage array at Kilroot Power Station in 2015. Dr Kubik is an honoree of the 2017 Forbes 30 Under 30 industry list and was named Young Energy Professional of the Year 2015 by the Energy Institute. 